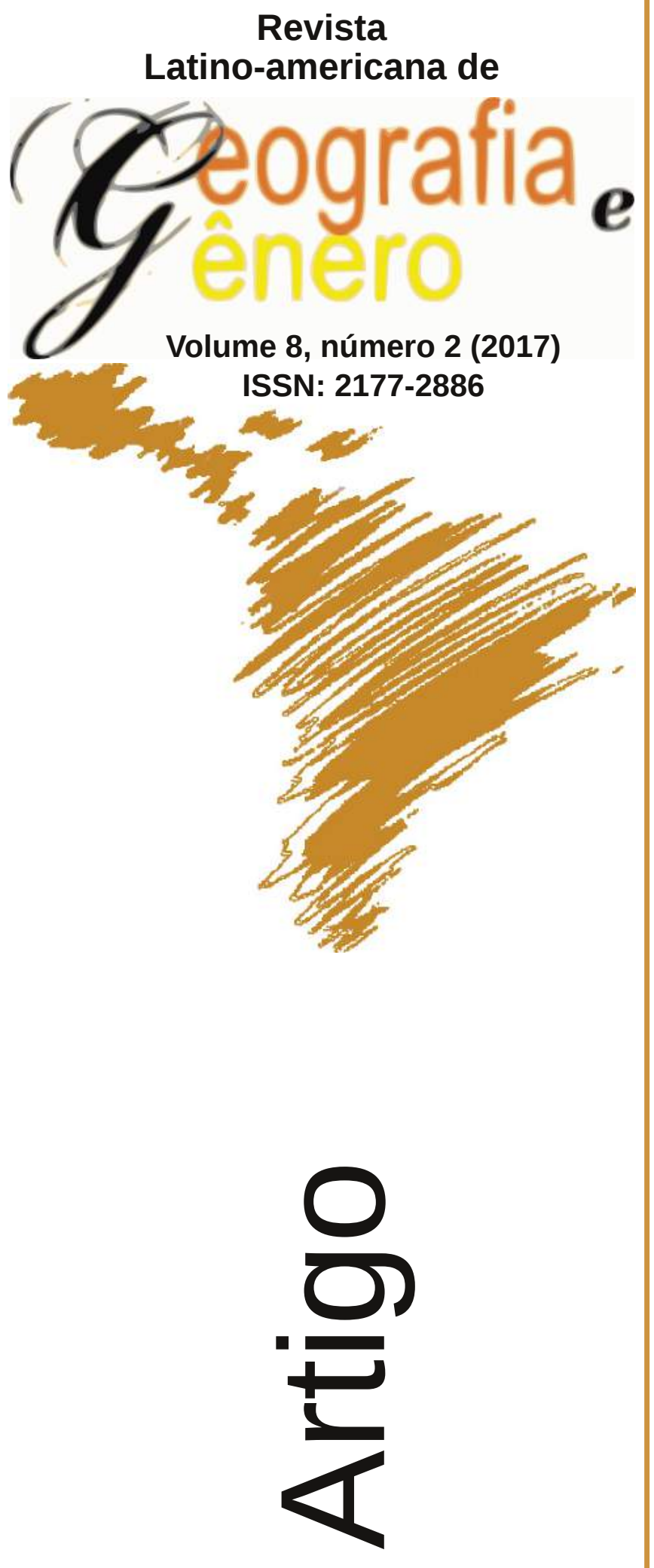

El Empoderamiento de las Mujeres en los Territorios de la Ciudadanía y las Elecciones de 2008 y 2012

The Empowerment of Women in the Territórios da Cidadania And The Elections of 2008 and 2012

Alides Baptista Chimin Junior Universidade Estadual do Centro Oeste - Brasil alides.territoriolivre@gmail.com

Ivan Jairo Junckes Universidade Federal do Paraná - Brasil ivanjairojunckes@gmail.com

Como citar este artigo:

CHIMIN JUNIOR, Alides Baptista;JUNCKES, Ivan Jairo. O Empoderamento das Mulheres nos Territórios da Cidadania e as Eleições de 2008 e 2012. Revista Latino Americana de Geografia e Gênero, v. 8, n. 2, p. 183-206, 2017. ISSN 2177-2886.

Disponível em:

http://www.revistas2.uepg.br/index.php/rlagg 


\title{
O Empoderamento das Mulheres nos Territórios da Cidadania e as Eleições de 2008 e 2012
}

\author{
El Empoderamiento de las Mujeres en los Territorios de la Ciudadanía y las \\ Elecciones de 2008 y 2012
}

\section{The Empowerment of Women in the Territórios da Cidadania And The Elections of 2008 and 2012}

\section{Resumo}

Este artigo visa a analisar as relações entre os projetos destinados às mulheres no programa federal dos Territórios da Cidadania (TC) e as mudanças ocorridas na participação das candidatas e eleitas ao cargo de vereador nas eleições de 2008 e 2012 nessas regiões. O trabalho centra a análise nos registros de candidaturas, nos resultados eleitorais e nas redes de financiamento eleitoral. As fontes de dados e informações foram coletadas no sítio eletrônico do Ministério do Desenvolvimento Agrário, então responsável pelo Programa Territórios da Cidadania, e no sítio do Tribunal Superior Eleitoral (TSE). Dados suplementares sobre os municípios foram também obtidos no Instituto Brasileiro de Geografia e Estatística (IBGE). Os dados foram organizados em forma de banco de dados e preparados para a geração de arquivos de redes que foram submetidos ao software Gephi de análise de redes sociais. Os resultados demonstram um considerável aumento da participação político-eleitoral das mulheres nos TC acima da média nacional na condição de candidatas e uma tímida ampliação das mulheres na ocupação das cadeiras de vereador nos municípios estudados. Para análise dessas mudanças são utilizados o posicionamento das candidatas nas redes de financiamento e as mudanças no perfil dessas mulheres.

Palavras-Chave: Gênero; Mulheres; Eleições; Financiamento Eleitoral.

\section{Resumen}

Este artículo busca analizar las relaciones entre los proyectos destinados a las mujeres en el programa federal de los Territorios de la Ciudadanía (TC) y los cambios ocurridos en la participación de las candidatas y elegidas al cargo de concejal en las elecciones de 2008 y 2012 en esas regiones. El trabajo centra el análisis en los registros de candidaturas, en los resultados electorales y en las redes de financiación electoral. Las fuentes de datos e informaciones fueron recolectadas en el sitio electrónico del Ministerio de Desarrollo Agrario, entonces responsable del Programa Territorios de la Ciudadanía, y en el sitio del Tribunal Superior Electoral (TSE). Los datos suplementarios sobre los municipios también se obtuvieron en el Instituto Brasileño de Geografía y Estadística (IBGE). Los datos fueron organizados en forma de base de datos y preparados para la generación de archivos de redes que fueron sometidos al software Gephi de análisis de redes sociales. Los resultados demuestran un considerable aumento de la participación político-electoral de las mujeres en los TC por encima del promedio nacional en la condición de candidatas y una tímida ampliación de las mujeres en la ocupación de los escaños de concejal en las ciudades estudiadas. Para el análisis de estos cambios se utiliza el posicionamiento de las candidatas en las redes de financiamiento y los cambios en el perfil de esas mujeres.

Palabras-Clave: Género; Mujeres; Elecciones; Financiamiento Electoral. 
This article aims to analyze the relationships between projects for women in the federal program Territórios da Cidadania (TC) and changes that occurred in the participation of women candidates and elected to the position of city councilor in the 2008 and 2012 elections in these regions. The paper focuses the analysis on application records, electoral results and electoral financing networks. The sources of data and information were collected on the Ministério de Desenvolvimento Agrário website, which was then responsible for the program Territórios da Cidadania, and on the website of the Tribunal Superior Eleitoral (TSE). Supplementary data on municipalities were also obtained from the Instituto Brasileiro de Geografia e Estatística (IBGE). The data were organized in the form of a database and prepared for the generation of files of networks that were submitted to Gephi social network analysis software. The results show a considerable increase in women's political-electoral participation in TC above the national average as candidates and a timid increase in the number of women occupying council seats in the municipalities studied. To analyze these changes are used the positioning of the candidates in the financing networks and the changes in the profile of these women.

Palabras-Clave: Gender; Women; Elections; Electoral Financing. Introdução

Nos Anos 90 a geografia política foi fortemente influenciada pela força teórica dos argumentos de David Harvey (1989) e Peter Jackson (1989), fazendo surgir uma vertente que assume como elemento de investigação as identidades e as diferenças culturais como a etnicidade, a religião e a linguagem, trazendo para as abordagens do campo as políticas da diferença. No começo do século XXI, Staeheli e Kofman (2004) argumentam que os termos como pertencimento e inclusão tornaram-se constantes nos argumentos da geografia política, notadamente porque eles falam sobre processos de democratização e da incorporação dos sujeitos políticos como cidadãos. Todavia, estas geógrafas políticas também apontam que as promessas de garantia de cidadania e direitos universais passaram a ser questionadas, pois mesmo frente ao estabelecimento de mecanismos formais de democracia, parte dos grupos sociais estão excluídos dos processos de participação política. $\mathrm{O}$ presente trabalho discute esta temática e apresenta resultados da análise de um grande programa de inclusão cidadã implantado no Brasil na última década, denominado Territórios da Cidadania (TC).

Regulamentado em 2008, o TC trouxe em sua estrutura legal o amparo universalista e também possibilidades para trabalhar a cidadania contemplando a diversidade em seu espaço de implantação, pois além de reconhecer a diversidade de gênero, raça e etnia, também possibilita que os projetos desenvolvidos em cada território sejam construídos e desenvolvidos pelos moradores e moradoras destas localidades.

O Programa Territórios da Cidadania está articulado a partir de convênios nas esferas públicas federal, estadual e municipal, bem como consórcios públicos, entidades de direitos humanos público ou privado sem fins lucrativos e se apoia em três eixos de atuação sendo: ação produtiva, cidadania e infraestrutura. O TC assume caráter geográfico ao identificar o espaço pela sua diversidade de carências sociais. Enquanto política pública, este deve criar 
ações positivas para o combate das diversas carências sociais dentre os distintos territórios.

O programa teve como objetivo promover o desenvolvimento econômico e universalizar programas básicos de cidadania por meio de uma estratégia de desenvolvimento territorial sustentável. Para regulamentar o programa, foram selecionados os municípios com os piores índices de desigualdade social do país, agrupados segundo critérios sociais, culturais, geográficos e econômicos, devem ter até cinquenta mil habitantes e apresentar densidade populacional média abaixo de oitenta habitantes por $\mathrm{km}^{2}$. De acordo com o Decreto Federal 11.503 de 25 de fevereiro de 2008 :

Art. 2 O Programa Territórios da Cidadania tem por objetivo promover e acelerar a superação da pobreza e das desigualdades sociais no meio rural, inclusive as de gênero, raça e etnia, por meio de estratégia de desenvolvimento territorial sustentável que contempla:

I - integração de políticas públicas com base no planejamento territorial;

II - ampliação dos mecanismos de participação social na gestão das políticas públicas de interesse do desenvolvimento dos territórios;

III - ampliação da oferta dos programas básicos de cidadania;

IV - inclusão e integração produtiva das populações pobres e dos segmentos sociais mais vulneráveis, tais como trabalhadoras rurais, quilombolas, indígenas e populações tradicionais;

V - valorização da diversidade social, cultural, econômica, política, institucional e ambiental das regiões e das populações.

Com base nos critérios definidos pelo decreto e a instituição do comitê gestor, em 2008 e 2009 foram selecionados 1.852 municípios agrupados em 120 Territórios da Cidadania, abrangendo $32,9 \%$ do total de municípios do Brasil. Conforme dados do IBGE (2010) estes municípios juntos possuem 42,4 milhões de habitantes (23\% da população nacional) sendo 13,1 milhões residentes no meio rural $(46 \%$ da população nacional que reside no meio rural). Conforme relatório apresentado pelo grupo gestor ${ }^{1}$, existem 525,1 mil famílias residindo em assentamentos (67\% do total nacional), 3,9 milhões de famílias atendidas pelo programa bolsa família (67\% do total nacional), 810 comunidades quilombolas (66\% do total nacional), 317 terras indígenas $(52 \%$ do total nacional) e 210,5 mil famílias de pescadores (54\% do total nacional). Os municípios que compõe o programa possuem um IDHM/PNUD ${ }^{2}$ inferior a 0,620, valor abaixo da média nacional, que é de 0,660. Com base na classificação do PNUD não foi identificado nenhum município com IDH muito alto nos municípios que compõe o programa. A Figura 1 a seguir apresenta a abrangência da distribuição dos TC por região no país.

1 Relatório disponível no endereço eletrônico http://www.territoriosdacidadania.gov.br acessado em 02/10/2013.

2 Índice de Desenvolvimento Humano por Município do Programa das Nações Unidas para o Desenvolvimento IDHM/PNUD. Consulta realizada no dia 01/08/2015 no endereço eletrônico: http://www.pnud.org.br

Alides Baptista Chimin Junior, Ivan Jairo Junckes 
O Empoderamento das Mulheres nos Territórios da Cidadania e as

\section{Eleições de 2008 e 2012}

Figura 1 - Territórios da Cidadania por Região no Brasil.

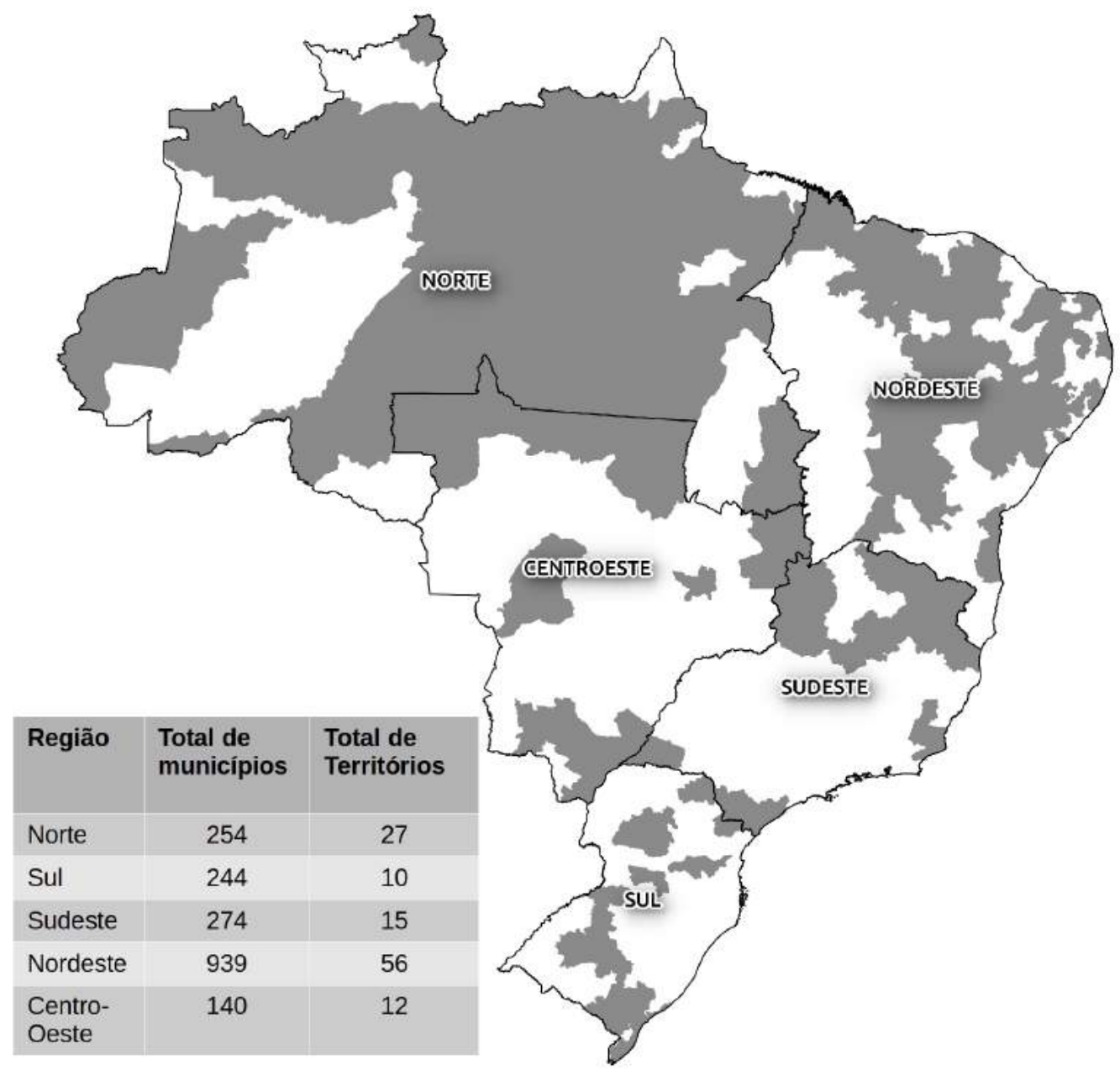

Fonte: Programa Territórios da Cidadania, 2014; IBGE, 2015. Organização própria.

Cada um dos 120 territórios Programa Territórios da Cidadania dispõe de um Colegiado Territorial composto por representantes governamentais e sociedade civil. Os colegiados propõem projetos a fim de solucionar demandas sociais específicas de suas regiões. Dentre os projetos propostos e aprovados para receber recursos financeiros, foram identificados na pesquisa 2.085 projetos voltados para as mulheres.

Entre os pilares do programa está a implantação de ações para a superação das desigualdades de gênero e empoderamento feminino nas estruturas econômicas e políticas da sociedade. Dentre os maiores desafios para este fím está a representação de interesses das mulheres na esfera formal do Estado e isso se dá principalmente por meio das disputas eleitorais. Todavia, nos 1.852 municípios que compõem o TC apenas $20,4 \%$ das candidaturas nas eleições de 2008 foram de mulheres. Dentre os eleitos, apenas 13,3\% são de mulheres. Em 2012, as candidaturas de mulheres alcançaram $27,1 \%$ e a participação feminina entre os eleitos foi $14,4 \%$. Embora tenha sido ampliada, a participação de mulheres entre eleitos ainda não alcança sequer duas para cada oito homens.

Nas eleições de 2008, a participação eleitoral das mulheres nos municípios que compõe o Programa Territórios da Cidadania foi muito próxima ao 
|| verificado nos demais municípios brasileiros. Todavia, nas eleições de 2012 houve um crescimento tanto de candidaturas quanto de mulheres eleitas nos TC. O presente artigo analisa a relação entre as políticas de empoderamento das mulheres promovidas no programa federal dos Territórios da Cidadania a partir de 2008 e a participação feminina nas eleições de 2008 e 2012, especialmente na representação das câmaras de vereadores.

Para a realização da pesquisa foram sistematizados os relatórios gerenciais dos 120 Território da Cidadania, disponibilizados pelo Ministério do Desenvolvimento Agrário, identificando quais projetos foram executados e quais os valores investidos pelo governo federal em cada território entre os anos de 2008 e 2012. Os dados sobre as candidaturas e contas de campanha das eleições de 2008 e 2012 foram coletadas no portal de eleições do Tribunal Superior Eleitoral (TSE). Os dados foram organizados em um banco de dados próprio $^{3}$ em PostgreSQL e submetidos para análise em testes estatísticos e no software de análise de redes Gephi ${ }^{4}$. Foram também estruturadas duas grandes redes com dados de financiamento (doadores, candidatos e agentes partidários), uma referente às eleições de 2008 e outra relativa às eleições de 2012.

A rede de financiamento eleitoral de 2008 contém 340.759 nós (candidatos e financiadores) e 301.417 arestas, assim denominados os relacionamentos existentes entre financiadores e candidatos. Os nós da rede de 2008 são compostos por $76,3 \%$ de doadores, $22,2 \%$ de candidaturas ao cargo de vereador e $1,5 \%$ de candidaturas a prefeito. A rede de financiamento eleitoral de 2012 está composta por 496.046 nós e 378.269 arestas, sendo que 79,6\% dos nós são doadores; $19,4 \%$ são candidaturas ao cargo de vereador e $0,1 \%$ candidaturas a prefeito. Para ambas as redes foram executadas as operações estatísticas própria da análise de rede para identificar grau médio ${ }^{5}$, grau ponderado médio ${ }^{6}$, diâmetro da rede $^{7}$, densidade do grafo $^{8}$, modularidade ${ }^{9} \mathrm{e}$ componentes conectados ${ }^{10}$. Estas operações resultam em novas tabelas com informações específicas de cada nó (candidato ou doador): grau ${ }^{11}$, grau de

1 Banco de dados desenvolvido com apoio da equipe do projeto 'O mapeamento do espaço das mulheres nas eleições de 2002, 2004, 2006, 2008, 2010 e 2012 no Brasil', aprovada pela chamada MCTI/CNPq/SPM-PR/MDA n³2/2012 e coordenado pela Dr ${ }^{\mathrm{a}}$ Joseli Maria Silva.

2 Software livre de criação e análise de redes sociais. Disponível em: http://gephi.github.io

5 Número de conexões que um nó da rede estabelece com outros nós.

6 A densidade de relações de um nó tem com outros nós.

7 Medida de distância entre os nós de uma rede.

8 Define o nível de conexão do grafo. Quanto maior o número de conexões entre os nós, mais denso se torna o grafo.

9 Medida de relações de comunidades da rede.

10 Número de nós e comunidades conectados na rede.

11 Número de conexões de um nó.

Alides Baptista Chimin Junior, Ivan Jairo Junckes 


\section{Eleições de 2008 e 2012}

entrada ${ }^{12}$, grau de saída ${ }^{13}$, weighted degree ${ }^{14}$, weighted in-degree ${ }^{15}$, weighted out-degree $^{16}$, closeness centrality ${ }^{17}$, betweenness centrality ${ }^{18}$, modularity class $^{19}$ e component $I D^{20}$.

A partir das duas grandes redes foram criadas 120 redes das eleições de 2008 e 120 redes de 2012, uma para cada território em cada eleição, totalizando 240 redes. Cada rede foi segmentada para identificar a sub-rede principal (componente gigante) e as sub-redes periféricas (componentes isolados). Neste processo foram gerados 480 grafos, sendo que cada território estava representado em dois grafos diferentes, um contendo o componente gigante e outro com os componentes isolados. Esta subdivisão foi uma opção metodológica a fim de reexecutar as estatísticas de rede e identificar o posicionamento de cada agente no seu agrupamento específico das sub-redes. Para cada sub-rede foram executados cálculos para identificar os componentes e obter métricas de rede (centralidades) que permitissem a análise específica da dinâmica relacional do financiamento eleitoral em cada território. Os dados armazenados no banco PostgreSQL foram acessados para construção de consultas (a fim de realizar análises) com uso dos softwares livres SOFA Statistic $^{21}$ e Libre Office Base ${ }^{22}$.

O artigo está organizado em duas sessões além desta introdução e de uma conclusão. Primeiramente discutimos sobre os desafios da geografia política e dos estudos de financiamento eleitoral para abordar o empoderamento feminino ocorrido através do voto. Na segunda sessão, são discutimos os resultados considerando o perfil das mulheres e sua posição na rede de

12 Número de conexões que um nó recebe.

13 Número de conexões que um nó realiza.

14 Valor total de atributo por meio de arestas conectadas ao nó.

15 Valor recebido de atributo por meio de arestas conectadas a outros nós.

16 Valor destinado de atributo por meio de arestas conectadas a outros nós.

17 Medida da centralidade de proximidade entre os nós.

18 Medida de intermediação atribui valor de fluxo transmitido pelo nó com outros nós.

19 Identifica comunidades no grafo.

20 Atribui valor identificando que o nó pertence a uma comunidade de nós que possuem conexões.

21 Software livre de análises estatísticas. Importante salientar que o SOFA consegue se conectar diretamente com o PostgreSQL. Software disponível em: http://www.sofastatistics.com

22 Software livre componente do pacote de escritórios (com editor de textos, planilha eletrônica, etc.) que permite inserir dados em bancos de dados (no caso o PostgreSQL) e também realizar consultas, conexões entre tabelas, etc. Disponível em: https://ptbr.libreoffice.org 
financiamento eleitoral. A inter-relação entre geografia, gênero, eleições (perfil de sucesso e redes de financiamento) é um grande desafio que o presente trabalho assume, porém ao alicerçar tais desafios, o trabalho se compromete em contribuir tanto com a discussão teórica e metodológica de uma geografia política feminista, quanto em dar visibilidade a estruturas que reproduzem a desigualdade de gênero na representação política.

\section{A Geografia Política e os Desafios para os Estudos do Empoderamento Feminino pelo Voto}

A geografia política feminista se constituiu preocupada com a transformação social e com as práticas sociais que muitas vezes podem estar além dos limites convencionais das políticas de Estado (KOFMAN e PEAKE, 1990). Todavia, experiências de grupos sociais marginais, durante muito tempo, estiveram ausentes dos Estudos da geografia política, as mulheres em geral constituíram um destes grupos. Staeheli, Kofman e Peake (2004), em sua análise sobre a geografia política feminista, argumentam que o campo científico foi produzido com base em três abordagens sobre a política que são sobrepostas: a abordagem da política como distribuição, a política como antagonismo e a política como constitutiva.

As geógrafas políticas defendem que as questões que envolvem gênero são fundamentais para compreender a política distributiva, que evidencia a distribuição do poder sobre os recursos e privilégios da sociedade por meio de adquirir a capacidade de controle das instituições e de usar a distribuição dos recursos para atingir determinados objetivos. A compreensão da política como constitutiva implica compreender a política como um processo contínuo, no qual as sociedades são instituídas através de tensões e lutas. Disputas sociais complexas, antagônicas e polivalentes envolvem ações, comportamentos e recursos tanto em espaços formais do Estado como das escalas do bairro, da casa, do local de trabalho, da comunidade religiosa e da mídia.

Borges e Maschietto (2014) compreendem o movimento de participação e subversão de espaços controlados por atores externos centrais como empoderamento para a cidadania, tal qual o faz Horochovski (2007, p.112) ao considerar empoderamento como "o processo pelo qual indivíduos, organizações e comunidades angariam recursos que lhes permitam ter voz, visibilidade, influência e capacidade de ação e decisão". Ambos trazem em comum a dimensão espacial local, se referindo a atores específicos.

Novellino (2006) relata vários momentos históricos de empoderamento feminino que incluem a fundação do Partido Republicano Feminista (PRF) em 1910, a conquista do voto feminino no Rio Grande do Norte em 1927, a eleição da primeira mulher prefeita em Lajes (RN) em 1929, a conquista do voto feminino no Brasil em 193223, a posse da deputada federal Bertha Lutz em 1936 e da senadora Eunice Michiles em 1979. Podemos acrescentar nesta trajetória a posse da Presidenta Dilma Rousseff em 2011.

23 É importante lembrar que segundo o decreto $\mathrm{n}^{\circ} 21.076$, de 24 de fevereiro de 1932, as mulheres só poderiam votar com a autorização do marido. As mulheres viúvas e solteiras poderiam votar apenas se possuíssem renda própria.

Alides Baptista Chimin Junior, Ivan Jairo Junckes 
Mesmo com avanços históricos relacionados à participação feminina na política, a participação eleitoral de candidatas mulheres ainda é bastante reduzida. Com 9,9\% de mulheres deputadas federais e $16 \%$ senadoras na legislatura iniciada em 2014, o Brasil ocupa o $153^{\circ}$ lugar no mundo, e na América Latina fica à frente somente de Belize e Haiti, conforme dados da Inter-Parliamentary Union ${ }^{24}$.

Com o objetivo de ampliar a participação das mulheres candidatas no Brasil, foi criada a Lei 9.100/95 que estabeleceu uma cota de $20 \%$ para sexo feminino nos registros de candidaturas em cada partido político para as eleições de 1996. Em 1997 a cota eleitoral de gênero passou a ser de 30\%, tendo sido reafirmada pela minirreforma eleitoral de 2009. Apesar das mudanças na legislação, Alves e Pinto (2012) afirmam uma eficácia quase nula das medidas, que se reduziram a manobras protocolares quando a maioria dos partidos, a fim de "cumprir a cota", recrutaram "candidatas laranja". Em estudo específico sobre as cotas para as mulheres, Bolognesi (2012, p. 126) aponta que o pequeno incremento na participação das mulheres pode ser creditado a variáveis geracionais e não à legislação.

Analisando a década de 1990, Pinto (2001) aponta que o acesso à participação política pelas mulheres se deu por meio de ONGs enquanto que para os homens se deu por meio dos sindicatos. Para ambos, as organizações funcionaram como trampolim político para outras espacialidades, como no caso as câmaras de vereadores. Lisboa (2008), acrescenta que o empoderamento político das mulheres representa apenas um passo para o acesso às tomadas de decisão na esfera pública, e que a política enquanto instrumento emancipador tem que ser discutido em uma ampla e complexa análise que considere a categoria gênero.

A perspectiva de gênero ganhou ênfase na geografia política e tem produzido um discurso crítico sobre as maneiras pelas quais as distribuições e antagonismos de atores políticos, formam e transformam as sociedades. As desigualdades de gênero podem, e devem, ser objeto de estudo geográfico, tanto que para Iná de Castro (2005, p. 206) a geografia política deve indagar "de que modo o território expressa o exercício concreto da cidadania e, no Brasil, se é possível falar em uma cidadania territorialmente desigual e como indicar as raízes desta desigualdade".

Segundo Blacksel (2006), a geografia política eleitoral tem chamado atenção mais da ciência política do que da própria Geografia. Os padrões espaciais de resultados eleitorais podem construir uma visibilidade do poder, possuindo determinados enraizamentos territoriais que, tomados do ponto de vista da escala, podem ser bastante enriquecedores para compreender as relações de gênero na organização das redes de financiamento de campanhas políticas municipais.

No que tange às geografias do voto, enquanto subcampo da geografia

24 A média de participação feminina em cargos nos parlamentos superiores no mundo é de $22,6 \%$, com destaque para países Nórdicos que possuem uma média de 41,1\%. Na América Latina a Bolívia ostenta $53 \%$ de deputadas e $47 \%$ senadoras, Cuba se destaca com $49 \%$ de deputadas e o México com $42 \%$ de deputadas e $34 \%$ de senadoras. Dados disponíveis no endereço eletrônico: http://www.ipu.org/wmn-e/world.htm acessado em 18/08/2016.

Alides Baptista Chimin Junior, Ivan Jairo Junckes 
política, Burrel (2005) explora os processos de financiamento de campanhas políticas nos Estados Unidos, tomando como base um comparativo entre homens e mulheres. A autora contraria a tese de que as mulheres possuem maior dificuldade em angariar recursos para as campanhas políticas do que os homens e que, portanto, essa seria uma das causas da pequena participação feminina nos cargos eletivos. Apesar destas afirmações, Burrel (2005) conclui que há ainda uma sub-representação feminina na esfera do Estado, mas que isso deve ser compreendido a partir de elementos mais complexos, como os processos de campanha e os jogos de poder. Em seu trabalho, Secor (2005) evidencia que existem lógicas diferenciadas de acesso das mulheres às eleições, conforme a abrangência eleitoral. Segundo a autora, candidatas que são lançadas em uma escala nacional têm maior chance de sucesso eleitoral do que candidatas distritais. A autora aponta que distritos com maior número de cadeiras também conseguem eleger mais mulheres.

No Brasil, a geografia do voto tem apresentado uma produção ainda reduzida. No período entre 1937 e 2015 foram identificados apenas 14 artigos relacionados a "voto e eleições" publicados em periódicos classificadas no Sistema Quális Capes do campo da Geografia (Cesar, 2015). Dentre outros estudos $^{25}$ destacamos trabalhos que abordam a questão do financiamento eleitoral sob a perspectiva do conceito de gênero. Cervi (2010) analisa o financiamento eleitoral de 2008 nas capitais de Estado onde o autor enfoca na relação regional, das grandes capitais e o financiamento eleitoral. Azevedo (2012) problematiza os gastos eleitorais a partir das eleições de 1994 e analisa os exorbitantes valores eleitorais que revelam alguns agentes doadores como empresas, comércio, bancos, etc. Junckes et all (2015) aborda diretamente a participação e a posicionalidade periférica e excludente das mulheres nas redes de financiamento eleitoral no Brasil. Destacam-se também os trabalhos de Boas, Hidalgo e Richardson (2013), Bohn (2009), e Alves, Pinto e Jordão (2012) que analisam a dinâmica eleitoral assumindo como recorte a perspectiva de gênero.

As inovações propostas pelos estudos de grupos periféricos trazem o problema da escala como ponto fundamental da geografia política, notadamente a discussão da construção social da escala geográfica que possibilitará à perspectiva feminista construir a visibilidade das mulheres nas relações de poder que envolvem as campanhas eleitorais. Em diferentes escalas, a dinâmica eleitoral se manifesta com lógicas distintas. Uma mulher candidata ao cargo de vereador possui relações sociais diferentes de mulheres candidatas a deputado federal.

Por isso compreendemos que o trabalho envolvendo mulheres candidatas ao cargo de vereador nos municípios que compõe o Programa Territórios da Cidadania trará contribuições teóricas e metodológicas. Abordamos uma escala local com as candidatas ao cargo de vereador e ao mesmo tempo uma escala nacional, pois o Programa Territórios da Cidadania está presente em quarenta por cento do território Brasileiro e integra municípios com várias carências

25 Lencioni (1984), Dorfman (1997); César et all (2002); Silva (2005); Alencar (2005); Toledo (2007); Carvalho (2009); Barros (2010); Rodrigues (2012); Schurr (2012); Andrade et all (2012); Cunha (2013); Augusto et all (2013).

Alides Baptista Chimin Junior, Ivan Jairo Junckes 
O Empoderamento das Mulheres nos Territórios da Cidadania e as

\section{Eleições de 2008 e 2012}

sociais. O desafio que enfrentamos no presente trabalho é discutir o empoderamento de mulheres e comunidades que vivem em diferentes espacialidades.

\section{Os Projetos nos Territórios da Cidadania e a Ampliação da Participação das Mulheres Candidatas e Eleitas ao Cargo de Vereador nas Eleições 2008 e 2012}

Em um levantamento realizado no portal do Programa Territórios da Cidadania ${ }^{26}$, identificamos 15.207 projetos executados entre 2008 e 2012. Com a criação de um banco de dados destes programas, foi possível filtrar os programas orientados apenas para as mulheres, totalizando 2.085 programas. Embora o programa alcance a maior abrangência territorial na Região Norte, é na Região Nordeste onde estão concentrados os projetos, com uma média de 22 projetos por território tal qual pode ser observado na Figura 2 a seguir.

Figura 2 - Projetos voltados para as mulheres no período de 2008 a 2012 nos Territórios da Cidadania.

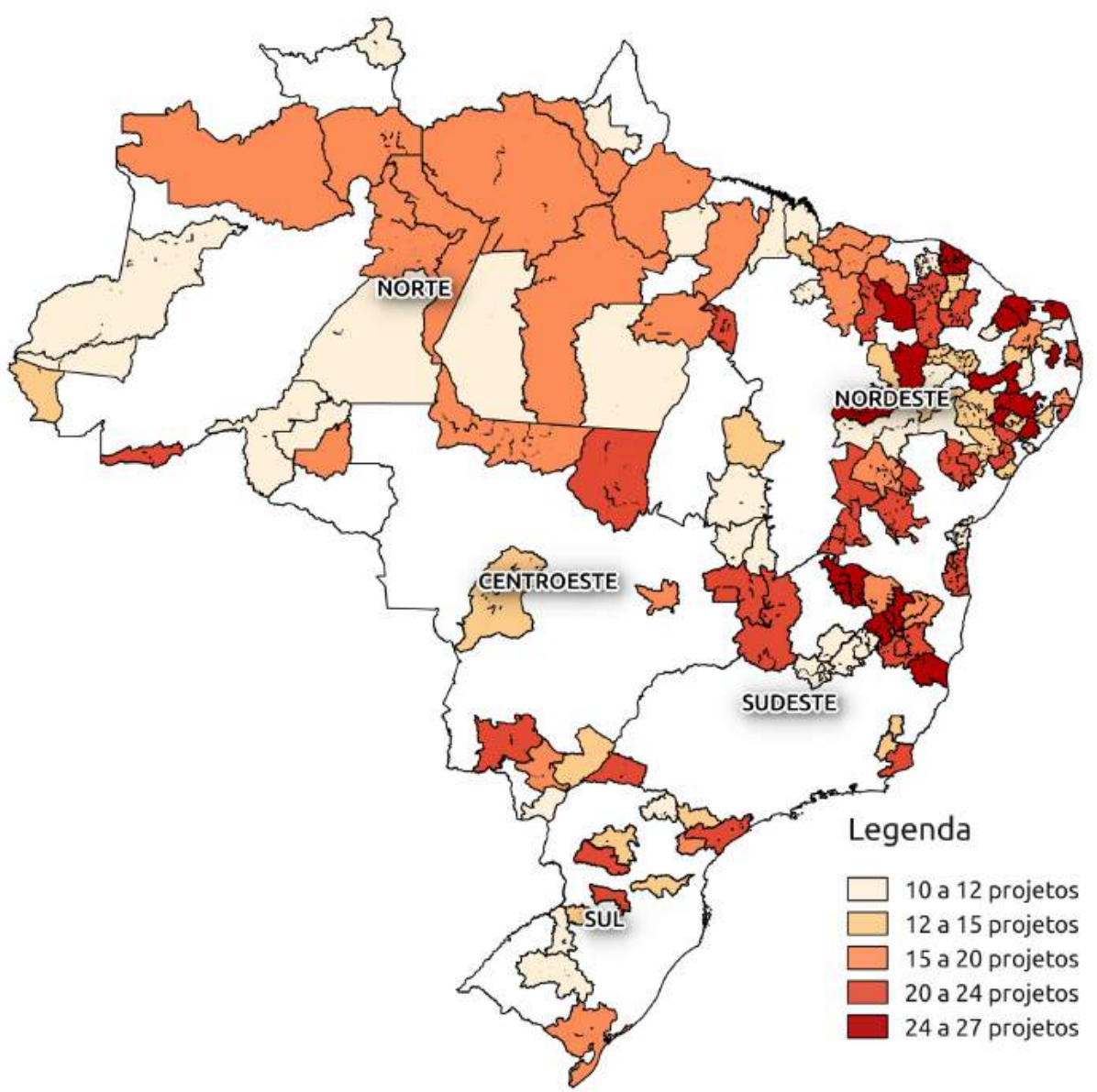

Fontes: Municípios IBGE, 2015. Programa Territórios da Cidadania, 2014. Organização própria.

26 Portal eletrônico http://www.territoriosdacidadania.gov.br acessado em 02/10/2013.. 


\section{Eleições de 2008 e 2012}

Quando agrupados os territórios, o último quartil (30 territórios dos 120) com maior número de projetos voltados para as mulheres, estes totalizam 757 projetos, concentrados na Região Nordeste. A Tabela 1, a seguir, relaciona os títulos dos projetos com a maior frequência no conjunto dos territórios.

Tabela 1 - Projetos voltados para as mulheres no Programa Territórios da Cidadania.

\begin{tabular}{|l|c|}
\hline Projeto & Total \\
\hline Programa de Atenção Integral à Família & 299 \\
\hline Infra-estrutura e Serviços nos Territórios Rurais & 298 \\
\hline Centros de Referência Especializados de Assistência Social - CREAS & 282 \\
\hline Programa Nacional de Documentação da Trabalhadora Rural (PNDTR) & 253 \\
\hline Programa Nacional de Crédito Fundiário & 157 \\
\hline Organização Produtiva das Mulheres Trabalhadoras Rurais & 144 \\
\hline Assistência Técnica e Extensão Rural (ATER) para Mulheres Rurais & 128 \\
\hline Formação de Agentes de Desenvolvimento & 120 \\
\hline Capacitação e Formação em Políticas Públicas para Mulheres Rurais & 84 \\
\hline Formação de Agentes de Desenvolvimento - Formação Complementar & 72 \\
\hline Programa Cisternas & 59 \\
\hline Acesso à Água para a Produção de Alimentos (2a Água) & 58 \\
\hline Formação de Agentes de Desenvolvimento - Formação Específica & 57 \\
\hline Formação de Lideranças em Políticas Públicas no PNDTR & 36 \\
\hline ProInfância & 23 \\
\hline
\end{tabular}

Fontes: Programa Territórios da Cidadania, 2014. Organização própria.

Dentre os diversos projetos listados na tabela acima, destacamos Capacitação e Formação em Políticas Públicas para Mulheres Rurais e Formação de Lideranças em Políticas Públicas no PNDTR ${ }^{27}$ como sendo os de maior potencial para a formação de lideranças políticas eleitorais. O projeto de Capacitação e Formação de Políticas Públicas para Mulheres Rurais tem como objetivo realizar ações de capacitação e formação em políticas públicas para mulheres rurais (Acesso à Terra, Documentação, Assistência Técnica e Extensão Rural - ATER/ATES, Crédito, Organização Produtiva, Comercialização e Desenvolvimento Territorial), visando a ampliação e qualificação do acesso das mulheres às políticas públicas, em especial às políticas de apoio à cidadania e desenvolvimento econômico por meio de convênios realizados com a Sempre Viva Organização Feminista (SOF) e o Centro Feminista 8 de Março (CF8). Já o projeto de Formação de Lideranças em Políticas Públicas no PNDTR tem como objetivo realizar ações de capacitação e formação em políticas públicas (Acesso à Terra, Documentação,

27 Programa Nacional de Documentação da Trabalhadora Rural.

Alides Baptista Chimin Junior, Ivan Jairo Junckes 
Assistência Técnica e Extensão Rural - ATER/ATES, Crédito, Organização Produtiva, Comercialização e Desenvolvimento Territorial, Cidadania, Combate à Violência contra a Mulher, Previdência Rural) para mulheres rurais, visando o combate à violência contra as mulheres.

O primeiro questionamento que se impõe é saber sobre a participação das mulheres nas eleições de 2008 e 2012 nos TC. Partindo da hipótese de que os projetos acima citados estimulam a participação política das mulheres e ampliam as chances de acesso ao legislativo municipal comparamos ambos os pleitos tanto nos territórios quanto com a média nacional.

O resultado é suficientemente claro. Em números absolutos ocorreu um crescimento de $19,6 \%$ de candidaturas para o cargo de vereador entre 2008 e 2012 no Brasil. Nos municípios que compõe o Programa Territórios da Cidadania esse crescimento foi de $27,0 \%$ de candidaturas, sendo que as mulheres apresentam um crescimento de $69,4 \%$ contra $16,2 \%$ dos homens, tal qual pode ser observado na Tabela 2 a seguir.

Tabela 2 - Valores gerais das redes nos pleitos de 2008 e 2012 nos municípios que compõe o Programa Territórios da Cidadania.

\begin{tabular}{|c|c|c|c|}
\hline & $\mathbf{2 0 0 8}$ & $\mathbf{2 0 1 2}$ & Dif. \% \\
\hline Total de candidatosl & 75.828 & 96.316 & 27,0 \\
\hline Homens & 60.389 & 70.172 & 16,2 \\
\hline Mulheres & 15.430 & 26.144 & 69,4 \\
\hline Homens eleitos & 13.924 & 15.982 & 14,7 \\
\hline Mulheres eleitas & 2.136 & 2.690 & 25,9 \\
\hline
\end{tabular}

Fonte: Banco de dados TSE disponível no GETE, 2014. Organização própria.

A participação de homens e mulheres no total de candidaturas aptas e no total de eleitos ao cargo de vereador nas duas eleições está representada no Gráfico 1 a seguir.

Gráfico 1 - Participação de homens (H) e mulheres (M) no total de candidaturas aptas e total de eleitos ao cargo de vereador nos pleitos de 2008 e 2012 nos municípios que compõe o Programa Territórios da Cidadania.

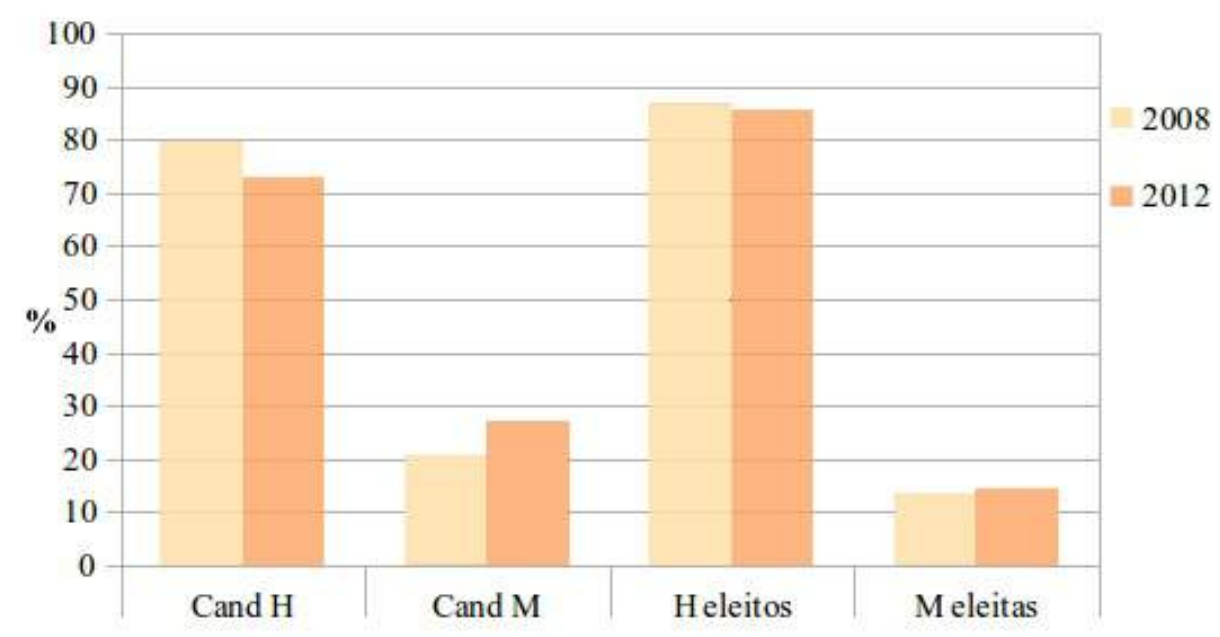

Elaboração própria com dados TSE.

Alides Baptista Chimin Junior, Ivan Jairo Junckes 
A participação de homens e mulheres candidatos em 2008 foi de 79,6 e 20,4 respectivamente, tendo sido de 72,9 e 27,1 em 2012. Evidencia-se uma significativa ampliação da participação feminina. Entre os vereadores eleitos a relação foi de 86,7 e 13,3 em 2008 e 85,6 e 14,4 em 2012, configurando um pequeno avanço na participação feminina.

Enquanto a participação das candidatas passou de 20 para $27 \%$, apresentando ampliação de 33\%; a participação das vereadoras eleitas passou de 13,3 para 14,4, apresentando um incremento de $8 \%$, suscitando uma investigação dos fatores que 'frearam' as chances de ampliação da participação feminina entre os eleitos. Dentre muitos fatores possível de serem estudados, investigamos inicialmente o posicionamento das mulheres na rede de financiamento eleitoral nos municípios dos TC.

\section{As Mudanças no Posicionamento das Mullheres nas Redes de Financiamento das Eleições entre 2008 e 2012: Trajetórias de Exclusão e Marginalização}

Seguindo modelo utilizado por Junckes et all (2015) e Silva et all (2017) investigamos o posicionamento das mulheres nas redes de financiamento realizando cortes topológicos nas respectivas redes a fim de identificar dentre os doadores e candidatos as relações de centralidade e periferia da rede, assumindo como pressuposto, tal qual demonstrado nos estudos citados, que o posicionamento central na rede de financiamento é determinante para as chances de sucesso eleitoral.

A primeira aproximação permitiu a identificação da participação das mulheres entre as candidaturas tornadas inaptas pela justiça eleitoral nas eleições de 2008 e 2012. Confirmamos a ocorrência, nos Territórios da Cidadania, do fenômeno que Pinto (2001) e Alves et all (2012) denominaram de 'mulheres laranja'. Tal adjetivo fora conferido pelos autores àquelas candidatas recrutadas pelos dirigentes partidários apenas para registro da nominata de candidatos, visando meramente cumprir a cota eleitoral prevista na lei $12.034 / 09$. Após o registro das candidaturas e, portanto o cumprimento formal da cota de participação feminina, as candidatas não apresentam a documentação complementar necessária para a confirmação da candidatura e são tornadas inaptas para a disputa eleitoral. A participação de homens e mulheres entre o total de candidaturas inaptas pode ser observado na Tabela 3 a seguir:

Tabela 3 - Percentual de candidaturas inaptas (cargo vereador) nas eleições de 2008 e 2012 nos municípios do Programa Territórios da Cidadania.

\begin{tabular}{|c|c|c|}
\hline & \% entre inaptos 2008 & \% entre inaptos 2012 \\
\hline Mulheres & $21,70 \%$ & $39,71 \%$ \\
\hline Homens & $78,30 \%$ & $60,29 \%$ \\
\hline TOTAL & $100,00 \%$ & $100,00 \%$ \\
\hline
\end{tabular}

Fonte: Banco de dados TSE disponível no GETE, 2014. Organização própria.. 
Tanto em 2008 quanto em 2012 foram declaradas inaptas 11\% das candidaturas registradas ao cargo de vereador nos TC. Todavia a participação das mulheres entre essas candidaturas passou de $21,7 \%$ para $39,7 \%$, enquanto entre os homens esse índice, de forma complementar, caiu de 78,3\% para $60,3 \%$. Ou seja, evidencia-se que parte significativa da ampliação da participação das mulheres fora 'freada' e frustrada no primeiro estágio do processo eleitoral. Tal qual apontam os estudos de Pinto (2001) e Alves et all (2012), o papel descompromissado dos dirigentes partidários, em geral homens, e o abandono das mulheres recrutadas pela organização partidária tem sido determinante para o resultado observado.

O segundo movimento para investigação do posicionamento das mulheres nas redes de financiamento eleitoral foi a identificação das mulheres entre os candidatos com menor centralidade na rede, ou seja, entre os mais periféricos. Os dois grafos a seguir, Figuras 3 e 4, são ilustrativos da posicionalidade periférica e central que discutimos nesta fase da investigação. O primeiro grafo ilustra a completa condição periférica dos participantes da rede, enquanto o segundo apresenta alguns nós (participantes) centrais e centenas, ou milhares, de outros também periféricos que se equivalem aos observados na primeira figura.

Figura 3 - Grafo da rede dos componentes isolados do território número 16 das eleições de 2008.

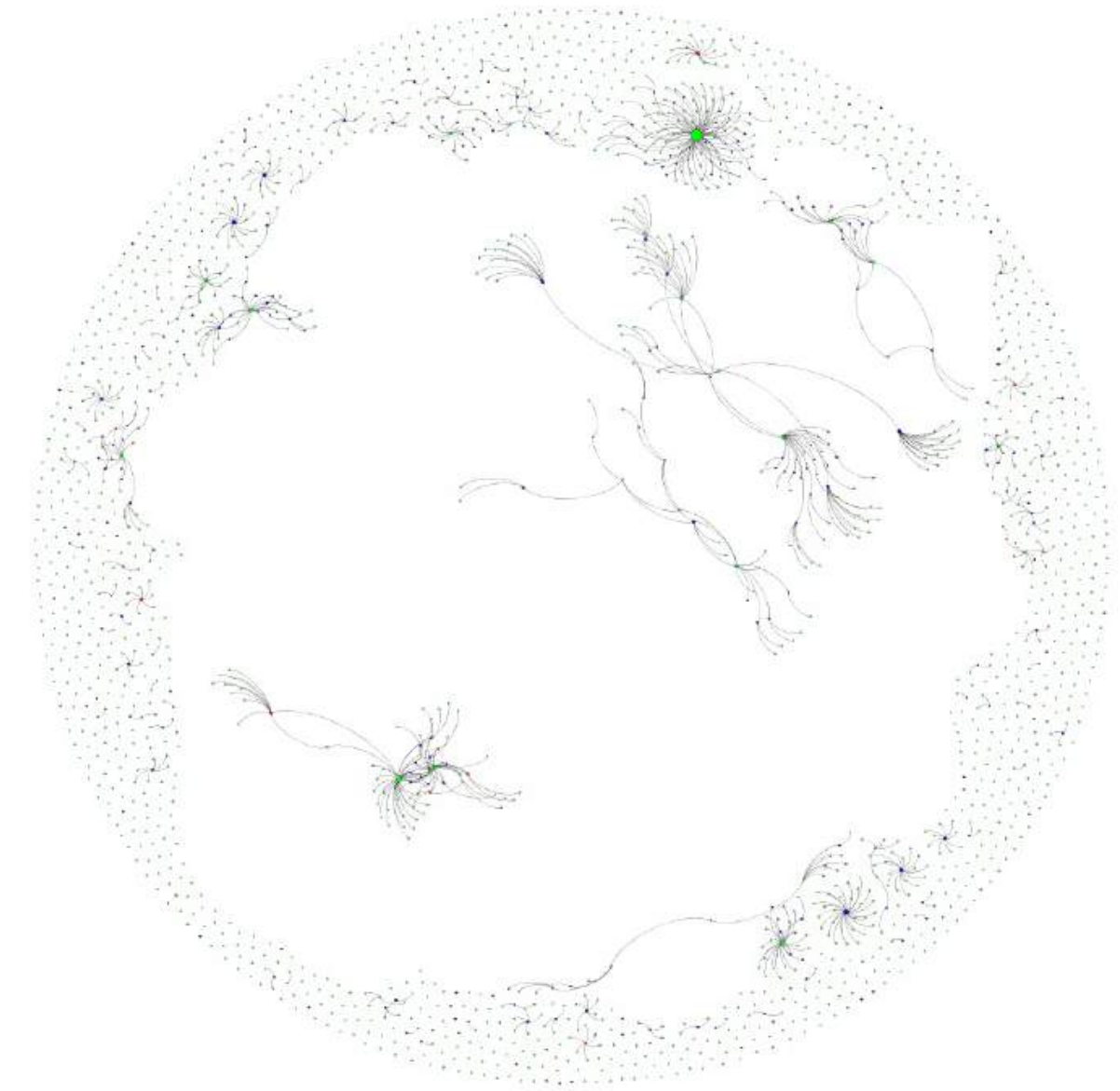

Fontes: Banco de dados TSE disponível no GETE, 2014. ${ }^{28}$ Organização própria. 
O Empoderamento das Mulheres nos Territórios da Cidadania e as

Eleições de 2008 e 2012

Figura 4 - Grafo da rede do componente gigante do território número 16 das eleições de 2008.

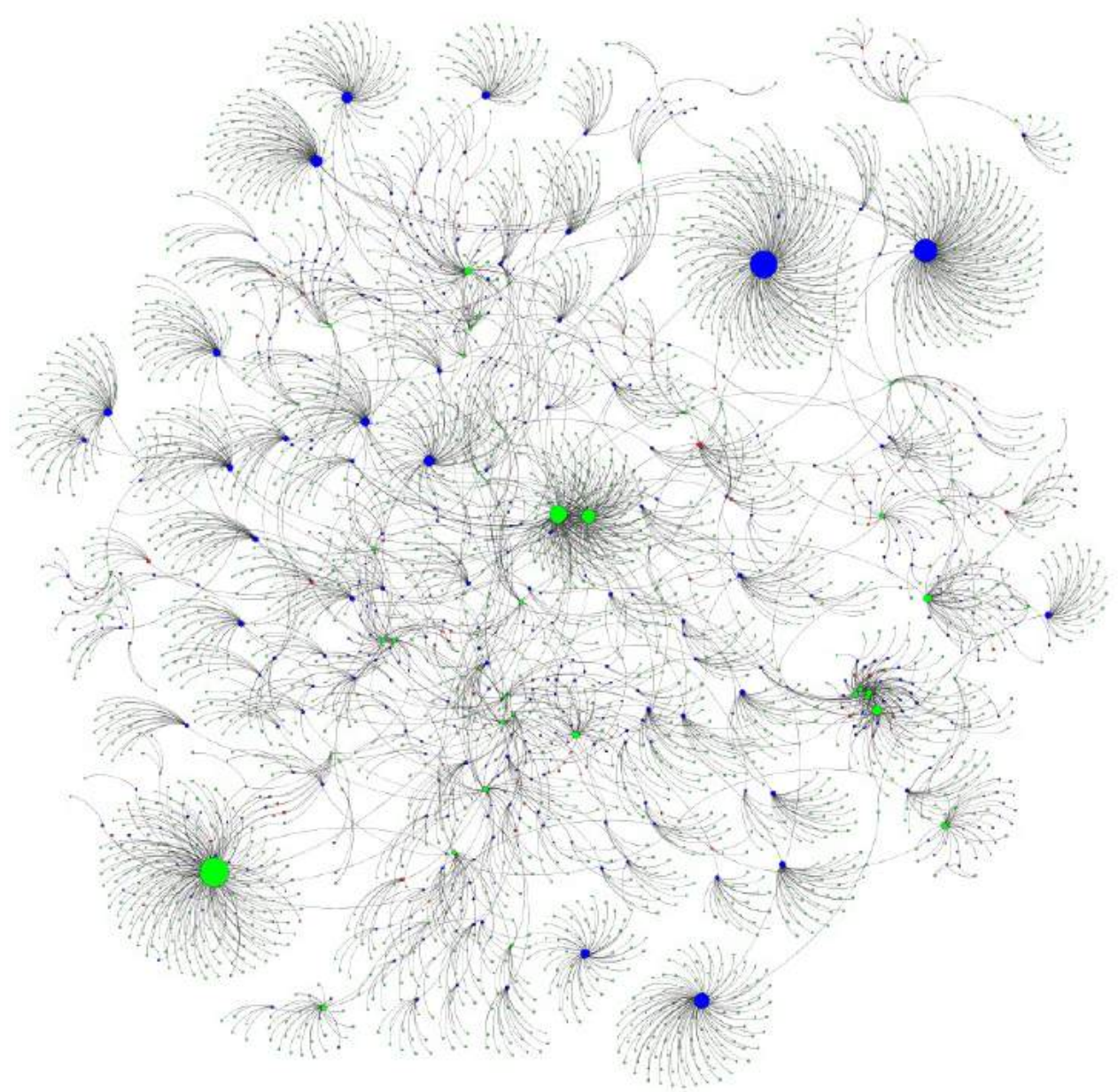

Fontes: Banco de dados TSE disponível no GETE, 2014. ${ }^{29}$ Organização própria.

Em 2008, 59,8\% das candidatas ao cargo de vereador faziam parte de redes periféricas nos municípios dos Territórios da Cidadania, enquanto que os homens eram 61,7\%, havendo pouca diferença proporcional. Já em 2012 houve uma redução das mulheres candidatas nas redes periféricas para 47,8\% assim como dos homens para 52,2\%. A comparação intersexos indica que em $2008,21,1 \%$ das redes periféricas era composta por mulheres e 78,9\% de homens. Já em 2012 houve um aumento na proporção de mulheres para 26,8\% e redução de homens, para os complementares $73,2 \%$. Ou seja, embora tenhamos observado uma maior integração na rede de 2012, esse fenômeno é menos intenso entre as candidatas mulheres. Novamente, a maior participação

28 Para acessar as redes de financiamento eleitoral assim como o atlas eleitoral dos pleitos de 2002 até 2012 de todos os municípios do Brasil, acesse: http://getepolitica.org/

29 Para acessar as redes de financiamento eleitoral assim como o atlas eleitoral dos pleitos de 2002 até 2012 de todos os municípios do Brasil, acesse: http://getepolitica.org/

Alides Baptista Chimin Junior, Ivan Jairo Junckes 
feminina, observada nos municípios dos Territórios da Cidadania, enfrentou uma estrutura que condiciona as mulheres em posições periféricas na rede de financiamento eleitoral.

O terceiro passo para estudo do posicionamento das mulheres nas redes de financiamento eleitoral nos municípios dos Territórios da Cidadania foi a análise da participação das mulheres nas posições centrais da rede. Em 2008, o componente central das redes era composto por 78,9\% de homens e $21,1 \%$ de mulheres. Em 2012, a participação dos homens reduziu-se para 72,1\% enquanto que a participação das mulheres ampliou-se para 27,9\%. Ou seja, esses resultados indicam que a ampliação de 33\% na participação das mulheres candidatas nos municípios dos territórios da cidadania entre 2008 e 2012 impulsionou a ampliação da participação proporcional das mulheres nos componentes centrais das redes de financiamento. Todavia, tal qual já evidenciado no Gráfico 1, tal incremento, de $8 \%$, pouco alterou a baixa participação das mulheres entre os eleitos.

Tendo obtidos esses resultados, passamos a investigar as diferenças entre o perfil das candidatas e das eleitas com o objetivo de melhor caracterizar a ampliação da participação político-eleitoral das mulheres nos municípios dos Territórios da Cidadania.

\section{As Mudanças no Perfil das Mulheres Candidatas nas Eleições de 2008 2012: Evidências de Empoderamento das Mulheres na Política?}

Utilizando os dados sobre as candidaturas, disponíveis no TSE (http://divulgacandcontas.tse.jus.br/divulga/\#/), montamos um banco de dados e realizamos buscas que possibilitem uma comparação parcial sobre as mulheres candidatas e eleitas vereadoras em 2008 e 2012 nos municípios dos Territórios da Cidadania. Os recortes de ocupação, escolaridade e pertencimento a partidos políticos sustentam as análises.

Nas eleições de 2008 a ocupação declarada pela maior parte das candidatas ao cargo de vereador nos municípios dos Territórios da Cidadania foi professora de ensino fundamental, seguido de donas de casa. Todavia, aquelas que apresentaram o maior sucesso no pleito já eram vereadoras e obtiveram a reeleição. De 696 candidatas cuja ocupação declarada foi Vereadora, 48\% delas foram reeleitas. Sucesso este seguido pelas professoras e servidoras públicas. Entre as donas de casa o sucesso eleitoral foi de apenas $8 \%$.

Nas eleições de 2012 o quadro ocupacional das candidatas e eleitas é bem semelhante. As candidatas donas de casa permanecem sendo uma categoria expressiva, todavia com sucesso eleitoral reduzido. As mulheres que obtêm maior êxito eleitoral são vereadoras, servidoras e professoras. Tal condição sugere que a realização dos projetos governamentais dirigidos para mulheres nos TC não influenciaram no perfil ocupacional das mulheres candidatas e eleitas nesses municípios. Evidentemente, restaria investigar a quais grupos sociais e categorias pertencem essas mulheres com maior sucesso eleitoral para avaliar alguma alteração possivelmente promovida por esses projetos.

O estudo do perfil de escolaridade das candidatas e eleitas ao cargo de vereador nos municípios dos TC foi razoavelmente mais revelador que o perfil ocupacional, embora estejam intrinsecamente associados. Como componente 
de integração social, esta variável é um importante elemento tanto da candidatura quanto no possível manejo interno dos partidos, pois uma pessoa bem instruída, hipoteticamente teria mais condições para argumentar politicamente e assim usufruir posicionamento político mais vantajoso.

Em 2008 a maior parte das candidaturas foram de mulheres com ensino superior incompleto (36,3\%), seguido de ensino fundamental incompleto $(25,1 \%)$ e superior completo (14\%). Entre as eleitas dois terços são ocupados por aquelas com ensino médio completo e superior completo. Nas eleições de 2012, a maior parte das candidatas possuíam ensino médio completo $(38,5 \%)$, seguido de mulheres com ensino superior completo $(25,3 \%)$. Interessante observar que o fato de os partidos terem inflado as nominatas com "mulheres laranjas" em 2012, com o objetivo de cumprir a cota formal de participação das mulheres, não provocou uma redução no perfil médio de escolaridade das candidatas. Entre as eleitas, o índice daquelas com ensino médio completo e superior completo passou de 67\% em 2008 para 77\% em 2012. Tal quadro sugere algum empoderamento das mulheres nos $\mathrm{TC}$, dado que a maior escolaridade representa maior possibilidade de acesso ao legislativo.

$\mathrm{O}$ avanço no perfil de escolaridade entre as eleitas nos municípios do TC corrobora os estudos de Speck e Sacchet (2012) ao argumentarem que as mulheres, em comparação aos homens, obtém melhores índices de escolaridade se comparado ao sucesso eleitoral. Já Miguel e Queiroz (2006), ao analisar especificamente a questão da instrução de mulheres em municípios menos desenvolvidos, compreendem que mesmo com baixos índices de escolaridade, estes municípios acabam recebendo destaque por candidaturas de mulheres com melhores escolaridades. Segundo os autores (id., p. 378) "a baixa escolaridade média nas regiões menos desenvolvidas abre uma oportunidade de inserção política para aquelas mulheres com nível de instrução mais alto". A instrução entra como categoria favorável não só no momento da candidatura, facilitando os trâmites burocráticos eleitoral, mas também como elemento diferencial entre as candidatas.

$\mathrm{O}$ estudo do perfil das candidatas e eleitas ao cargo de vereador nos municípios dos TC por filiação partidária e espectro ideológico também apresenta resultados bastante interessantes. Com uma ampliação da participação das mulheres candidatas sendo maior que o quadro nacional, os municípios dos TC apresentam uma distribuição relativamente uniforme do crescimento da participação feminina entre os partidos políticos, tal qual pode ser observado no Gráfico 2.

A categorização das candidatas eleitas por ideologia partidária1, baseado na categorização de Tarouco e Madeira (2013), revela o avanço de partidos de centro e o refluxo de partidos tanto à esquerda quanto à direita do espectro ideológico, vide Gráfico 3.

30 Foram considerados os seguintes espectros dos partidos: de Centro são PMDB, PRP, PSD, PSL, PT do B, PTB, PTN; Partidos Centro Direita: DEM, PHS, PP, PR, PRB, PTC.; Partidos Centro Esquerda: PDT, PMN, PPL, PPS, PSB, PSDB, PT, PV. Partidos de Direita: PRTB, PSC, PSDC. Partido de Esquerda: PSOL. Partidos de Extrema Esquerda: PC do B, PCB, PCO, PSTU. 


\section{O Empoderamento das Mulheres nos Territórios da Cidadania e as}

\section{Eleições de 2008 e 2012}

Gráfico 2 - Participação de mulheres no total de candidaturas ao cargo de vereador por partidos políticos nas eleições de 2008 e 2012, nos municípios que compõem o Programa Territórios da Cidadania.

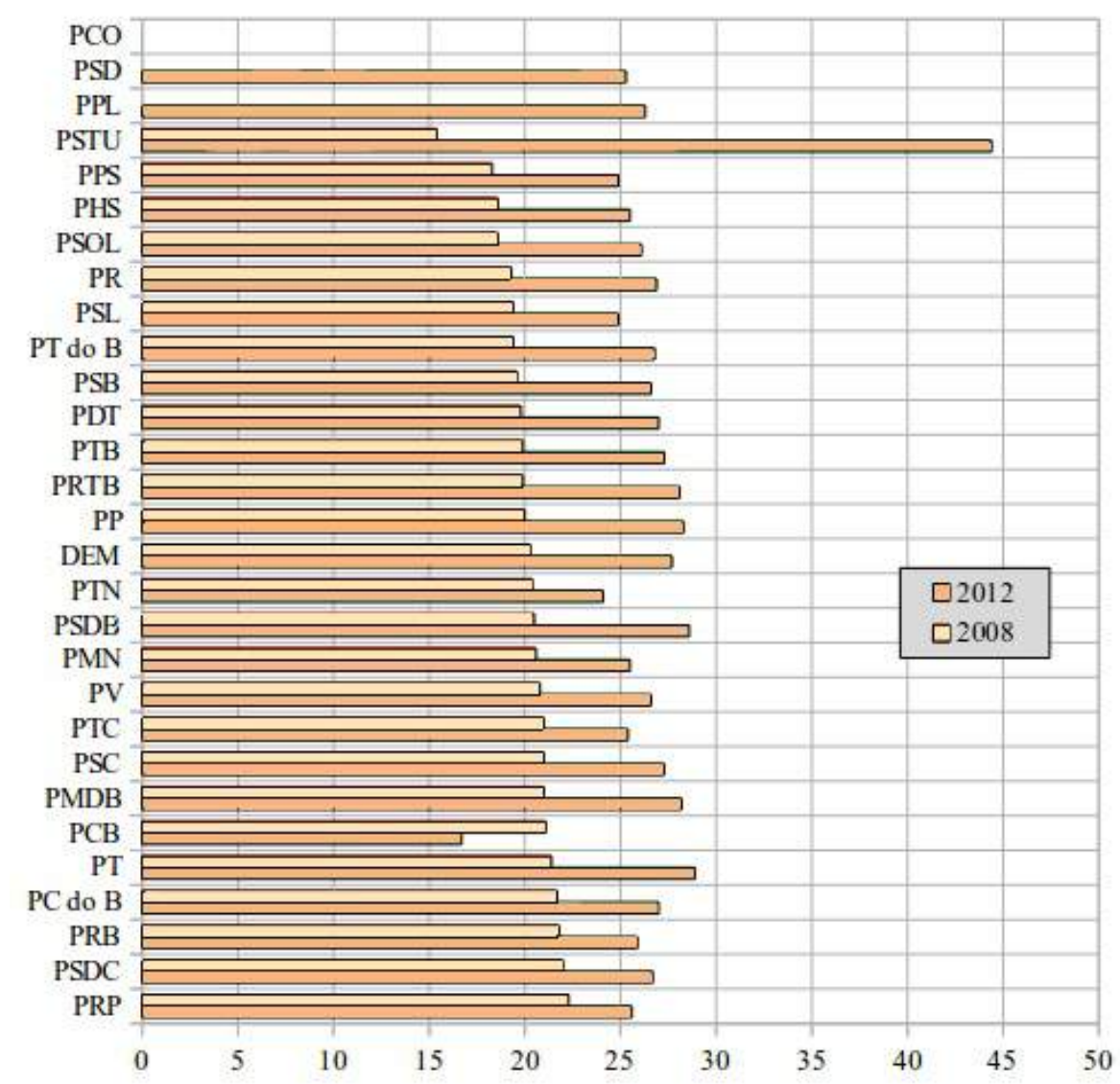

Fonte: TSE, 2012. Organização própria.

Gráfico 3 - Participação de mulheres eleitas no total de eleitos para o cargo de vereador por espectro político nas eleições de 2008 e 2012 ..

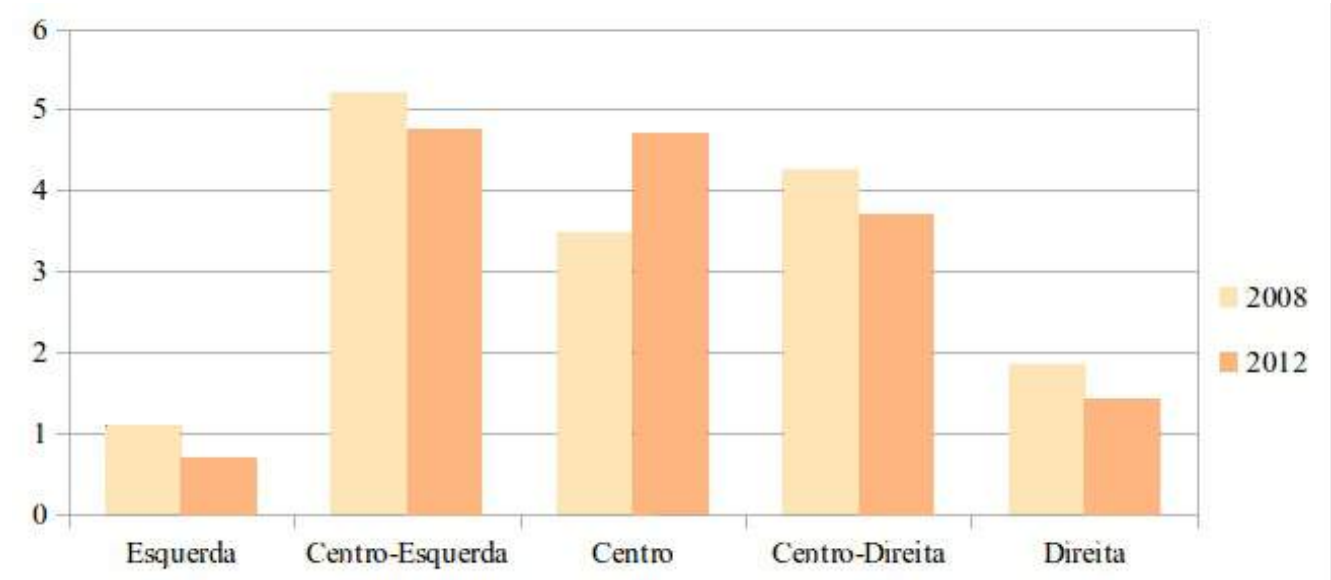

Fonte: TSE, 2012. Organização própria.

O fenômeno expresso no Gráfico 3, que pouco acompanha o quadro nacional para o mesmo período, sugere que as áreas que foram alvo de projetos do Programa Territórios da Cidadania impulsionaram a participação feminina com maior sucesso eleitoral em partidos identificados ao centro do espectro ideológico. 


\section{Conclusões}

A cidadania e o empoderamento feminino são conceitos permanentes nas lutas das mulheres e têm progressivamente ocupado a pauta de estudos acadêmicos. Ampliar a participação política feminina em espacialidades controladas por padrões patriarcais tornou-se política de governo nos municípios que compõem o Programa Territórios da Cidadania. Ante esta realidade, resolvemos investigar quais as relações entre os projetos destinados às mulheres nesses territórios e a participação delas nas eleições de 2008 e 2012 nessas regiões.

O primeiro avanço produzido pelo trabalho foi a escala de abordagem. O Programa Territórios da Cidadania foi abordado em escala nacional, esta dimensão exigiu uma série de esforços de coleta, organização e tratamento para a análise dos dados. A principal dificuldade superada foi a estruturação do banco de dados das eleições, disponíveis pelo TSE. As tabelas, além de serem grandes, necessitando de um servidor de banco de dados (PostgreSQL), foram concebidas para a prestação contábil das campanhas, o que limita a realização de análises estatísticas. Os dados de candidaturas e financiamento eleitoral também exigiram dedicação e capacidade de processamento. Para isso foi desenvolvida uma metodologia para converter a estrutura de dados financeiro em uma estrutura passível de uso em softwares de análise de redes sociais e de estatísticas. Os esforços bem-sucedidos permitem estabelecer uma frente de estudos e compartilhamento de conhecimentos sobre espaços que, apesar de todo o esforço de outros pesquisadores, em geral tem sido analisados de forma parcial.

O trabalho contribui para compreender os mecanismos de conquista e exclusão de uma cidadania carente de gênero. Demonstramos um aumento significativo de candidaturas nos TC, acima da média nacional nas eleições de 2012. Embora tal avanço não tenha sido integralmente incorporado na participação das mulheres entre os vereadores eleitos, também nesta arena as mulheres superaram a média de crescimento nacional.

Demonstramos que um dos fatores da "frenagem" entre a participação feminina entre os candidatos e entre os eleitos é a exclusão e marginalização das mulheres nas redes de financiamento eleitoral. Mas, foi possível também demonstrar uma considerável ampliação das mulheres em posições centrais nas relações de financiamento, e portanto, de poder nos círculos eleitorais.

Destaque-se entre as candidatas em posições periféricas, aquelas que cumprem o papel de mulheres laranja nas nominatas que visam tão somente cumprir a formalidade da legislação de cotas. As mulheres laranja em geral são abandonadas pela burocracia dos partidos políticos e acumulam pendências com a justiça eleitoral, tornando-se inelegíveis e impedidas de se candidatar nas próximas eleições, gerando uma participação cidadã às avessas. A lei de cotas, colhe portanto um efeito reverso, em vez de alavancar processo de empoderamento feminino, obtém como resultado restrições para uma eventual futura participação eleitoral das mulheres por ela atingidas reversamente.

Demonstramos também que as mudanças no perfil das mulheres candidatas e eleitas para o cargo de vereador nos municípios dos Territórios da Cidadania 
constituem fatores que podem ser associados e explicativos dos impactos dos programas federais executados nestes territórios e destinados ao apoio das mulheres. Esperamos com isto contribuir para a visibilidade do posicionamento do sujeito feminino nas estruturas de poder e na demanda de ações sociais para que o empoderamento feminino no âmbito do legislativo se torne uma práxis constante na ciência e na sociedade.

Concordamos com Feyerabend (1989) que nenhum processo de pesquisa científica é conclusivo. Pelo contrário, o ato de pesquisar e descobrir interpretações diferentes aos fenômenos é interminável. Esse processo de pesquisa, portanto, abre novos caminhos para futuros trabalhos sobre a participação das mulheres por meio do empoderamento local. Perseguimos no curso do trabalho de pesquisa as relações entre os projetos destinados às mulheres no programa federal dos Territórios da Cidadania e a participação das mulheres nas eleições de 2008 e 2012 nessas regiões. Os resultados apresentados, válidos nas condições para as quais são apresentados, devem ser considerados dependentes de um conjunto de outras variáveis que não foram objeto e tampouco estiveram ao alcance das investigações desenvolvidas. A pesquisa abordou o Programa Territórios da Cidadania em uma escala nacional, todavia alterando-se a variável escalar abre-se um leque de possibilidades para novas pesquisas, permitindo trazer novos questionamentos sobre como as relações de sociabilidade intercalam redes de empoderamento feminino nas estruturas de poder.

\section{Referências}

ALENCAR, Francisco Amaro Gomes de. Reflexões Sobre a Participação dos Assentados nas Eleições Municipais. Revista Nera, v. 8, n. 6, p. 59 - 74, 2005.

ALVES, José Eustáquio Diniz; PINTO, Céli Regina Jardim; JORDÃO, Fátima. Mulheres nas eleições 2010. São Paulo: $\mathrm{ABCP} / \mathrm{Secretaria}$ de Políticas para as Mulheres, 2012.

ANDRADE, Alex Jaison Barbos; VEIGA, C. CARVALHO, J. N. Geografia Politica Eleitoral Cabo-Verdiana: Mudança e Continuidade (1991-2011). Revista de Geografia (UFPE), v. 29, n. 3, p. 6 - 18, 2012.

AUGUSTO, Daniel Cirilo; SENE, Michael Wellington. Geografia Eleitoral e a Decisão do Voto: Estudo a Partir da Identificação Partidária. Revista Geonorte, v.7, n. 1, p. $81-97,2013$.

BARROS, Omar Neto Fernandes. Eleições no Paraná: 1998 2010. Confins, n. 10, p. 2010. Disponível em <http://journals.openedition.org/confins/6671>. Acesso em 28 de Dezembro de 2017.

BLACKSEL, Mark. Political Geography. New York: Routledge, 2006.

BOAS, Taylor C.; HIDALGO, F. Daniel; RICHARDSON, Neil P. The Spoils of Victory: Campaign Donations and Government Contracts in Brazil. Disponível em: <http://people.bu.edu/tboas/political_investment.pdf $>$. Acesso 
O Empoderamento das Mulheres nos Territórios da Cidadania e as

Eleições de 2008 e 2012

em 18 outubro de 2013.

BOHN, Simone. Mulheres brasileiras na disputa do legislativo municipal. Perspectivas, v. 35, p. 91 - 116, 2009.

BOLOGNESI, Bruno. A cota eleitoral de gênero: política pública ou engenharia eleitoral? Paraná Eleitoral - Revista Brasileira de Direito Eleitoral e Ciência Política, v. 1, n. 2, p. 107-29, 2012.

BORGES, Marisa; MASCHIETTO, Roberta Holanda. Cidadania e empoderamento local em contextos de consolidação da paz. Revista Crítica de Ciências Sociais, n. 105, p. 65 - 84, 2014.

BURREL, Barbara. Campaign Financing: Women's Experience in the Modern Era. In: THOMAS, Sue, WILCOX, Clyde. Women and elective office: past, present and future. Oxford: Oxford Press, 2005, p. 26 - 40.

CARVALHO, Nelson Rojas de. Geografia política das eleições congressuais: a dinâmica de representação das áreas urbanas e metropolitanas no Brasil. Cadernos Metrópole, v. 11, n. 22, p. 367 - 384, 2009.

CASTRO, Iná de. Geografia e política: território, escalas de ação e instituições. Rio de Janeiro RJ: Bertrand Brasil, 2005.

CESAR, Tamires Regina Aguiar de Oliveira. Gênero, Poder e Produção Científica Geográfica no Brasil de 1974 a 2013. 2015. Dissertação (Mestrado em Gestão do Território) - Universidade Estadual de Ponta Grossa, Ponta Grossa.

CÉSAR, Regina Célia Escudero; JURKEVICZ, Maristela R. A.; PIROLO, Maria Amélia Miranda; DI CHIARA, Ivone Guerreiro; MORENO, Nádina Aparecida; DALMAS, José Carlos; PATRIZZI, Carlos Antonio; CODATO, Henrique. Um Jeito Novo de Fazer Política: O Caso das Eleições Municipais de Londrina. Geografia, v. 11, n. 2, p. 229 - 239, 2002.

CUNHA, Ricardo Borges da. A Relação Entre a Distribuição Dos Votos e as Ações dos Vereadores no Município do Rio Grande nas Eleições de 2004. Revista Geonorte, v. 7, n. 1, p. 40 - 54, 2013.

DORFMAN, Adriana. A Geopolítica e 'O Perfil do Eleitor da Baixada Fluminense'. Boletim Gaúcho de Geografia, v. 22, p. 35 - 42, 1997.

FEYERABEND, Paul. Contra o Método. $3^{\text {a } e d ~ . ~ R i o ~ d e ~ J a n e i r o: ~ F r a n c i s c o ~}$ Alves, 1989.

HARVEY, David. The Condition of Postmodernity: an inquiry into the origins of social change. Blackwell, Oxford: 1989.

HOROCHOVSKI, Rodrigo Rossi. Desatando Nós: Associativismo civil, democracia e empoderamento na colônia de pescadores de Matinhos, 
O Empoderamento das Mulheres nos Territórios da Cidadania e as

Eleições de 2008 e 2012

Paraná. 2007. Tese (Programa de Pós-Graduação em Sociologia Política) Universidade Federal de Santa Catarina, Florianópolis.

JACKSON, Peter. Maps and Meaning. Unwin Hyman, London: 1989.

JUNKES, Ivan Jairo; HOROCHOVSKI, Rodrigo Rossi; CAMARGO, Neilor Fermino; SILVA, Joseli Maria; SILVA, Edson Armando; ALMEIDA, Leandro Batista. Posicionamento das Mulheres na Rede de Financiamento Eleitoral e seu Desempenho nas Eleições de 2010 no Brasil: A Dinâmica Estrutural da Exclusão e Marginalização Feminina no Poder Político. Revista Latinoamericana de Geografia e Gênero, v. 6, n. 1, p. 25 - 47, 2015.

KOFMAN, Eleonore; PEAKE, Linda Peake. Into the 1990s: A gendered agenda for political geography. Political Geography Quarterly, v. 9, p. 313-336, 1990.

LENCIONI, Sandra. Conservadorismo e Urbanização: Trinta Anos de Eleições Municipais (1947-1976). Revista do Departamento de Geografia da USP, v. 3, p. $63-80,1984$.

LISBOA, Teresa Kleba. O Empoderamento como estratégia de inclusão das mulheres nas políticas sociais. In: Fazendo o Gênero 8 - Corpo, Violência e Poder, Anais... Florianópolis, UFSC, 2008.

MIGUEL, Luis Felipe; QUEIROZ, Cristina Monteiro de. Diferenças regionais e o êxito relativo de mulheres em eleições municipais no Brasil. Estudos Feministas, v. 14, n. 2, p. $363-385,2006$.

NOVELLINO, Maria Salet Ferreira. As Organizações Não-Governamentais (ONGs) Feministas Brasileiras. In: XV Encontro Nacional de Estudos Populacionais, ABEP, Anais... Caxambú- MG, 2006.

PINTO, Céli Regina Jardim. Paradoxos da participação política da mulher do Brasil. Revista USP, n. 49, p. 98 - 112, 2001.

RAFFESTIN, Claud. Por uma Geografia do poder. São Paulo: Editora Ática, 1993.

RODRIGUES, Jean Carlos. Identidade, Política e Eleição no Estado do Tocantins: 1988-2010. Boletim Goiano de Geografia, v. 32, n. 2, p. 127 137, 2012.

SCHURR, Carolin. Pensando Emoções a Partir de uma Perspectiva Interseccional: As Geografias Emocionais das Campanhas Eleitorais Equatorianas. Revista Latino-americana de Geografia e Gênero, v. 3, n. 2, 2012.

SECOR, Anna J. Feminizing Electoral Geography In: STAEHELI Lynn A.; KOFMAN Eleonore, PEAKE Linda. Mapping women, making politics: feminist perspectives on political geography. New York: Taylor \& Francis e- 
O Empoderamento das Mulheres nos Territórios da Cidadania e as

Eleições de 2008 e 2012

Library, 2005, p. $261-272$.

SILVA, Alex Marciel da. Espacialização Demográfica e Voto Distrital nas Eleições Executivas do Ano 2000 na Cidade de Uberlândia (MG). Caminhos de Geografia, v. 8, n. 14, p. 78 - 97, 2005.

SILVA, Edson Armando; JUNCKES, Ivan Jairo ; HOROCHOVSKI, Rodrigo Rossi; CAMARGO, Neilor; SILVA, Joseli Maria. Mulheres nas eleições de 2014 no Brasil: evidências de exclusão e marginalização política. Revista latino-americana de Geografia e Gênero, v. 8, p. 251 - 272, 2017.

SPECK, B, W.; SACCHET, T. Patrimônio, instrução e ocupação dos candidatos: uma análise das candidaturas de mulheres e homens nas eleições gerais de 2010 no Brasil. In: ALVES, J. E. D.; PINTO, C. R. J.; JORDÃO, F. (Org.) Mulheres nas eleições 2010. São Paulo: ABCP/Secretaria de Políticas para as Mulheres, 2012.

STAEHELI, Lynn A.; KOFMAN, Eleonore; PEAKE, Linda. Mapping women, making politics: feminist perspectives on political geography. New York: Routledge, 2004.

TAROUCO, Gabriela Silva da; MADEIRA, Rafael Machado. Partidos, programas e debates sobre esquerda e direita no Brasil. Revista de Sociaologia e Política, v. 21, n. 45, p.149 - 165, 2013.

TOLEDO, Rubens Junior de. O Lugar e as Eleições: A Expressão Territorial do Voto no Brasil. GeoTextos, v. 3, n. 1/2, p. 171 - 183, 2007.

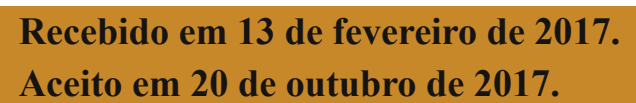

Alides Baptista Chimin Junior, Ivan Jairo Junckes 